\title{
Potential Effects of Silymarin and Its Flavonolignan Components in Patients with $\beta$-Thalassemia Major: A Comprehensive Review in 2015
}

\author{
Hadi Darvishi Khezri, ${ }^{1}$ Ebrahim Salehifar, ${ }^{2}$ Mehrnoush Kosaryan, ${ }^{1}$ Aily Aliasgharian, ${ }^{1}$ \\ Hossein Jalali, ${ }^{1}$ and Arash Hadian Amree ${ }^{1}$ \\ ${ }^{1}$ Thalassemia Research Center, Mazandaran University of Medical Sciences, Sari, Iran \\ ${ }^{2}$ Faculty of Pharmacy, Thalassemia Research Center, Mazandaran University of Medical Sciences, Sari 48175-861, Iran \\ Correspondence should be addressed to Ebrahim Salehifar; Esalehifar@mazums.ac.ir
}

Received 3 November 2015; Revised 21 January 2016; Accepted 27 January 2016

Academic Editor: Mahmoud S. Ahmed

Copyright (C) 2016 Hadi Darvishi Khezri et al. This is an open access article distributed under the Creative Commons Attribution License, which permits unrestricted use, distribution, and reproduction in any medium, provided the original work is properly cited.

\begin{abstract}
Major $\beta$-thalassemia $(\beta-\mathrm{TM})$ is one of the most common inherited hemolytic types of anemia which is caused as a result of absent or reduced synthesis of $\beta$-globin chains of hemoglobin. This defect results in red blood cells lysis and chronic anemia that can be treated by multiple blood transfusions and iron chelation therapy. Without iron chelation therapy, iron overload will cause lots of complications in patients. Antioxidant components play an important role in the treatment of the disease. Silymarin is an antioxidant flavonoid isolated from Silybum marianum plant. In the present study, we reviewed clinical and experimental studies investigating the use of silymarin prior to September 1, 2015, using PubMed, ISI Web of Knowledge, Science Direct, Scopus, Ovid, and Cochrane Library databases and we evaluated the potential effects of silymarin on controlling the complications induced by iron overload in patients with $\beta$-TM. Based on the results of the present study, we can conclude that silymarin may be useful as an adjuvant for improving multiple organ dysfunctions.
\end{abstract}

\section{Introduction}

$\beta$-Thalassemia $(\beta$-TM) is a chronic hereditary disease with a high prevalence in the Mediterranean region, Middle East, Indian subcontinent, and South East Asia. So far, around 230 different mutations have been reported on $\beta$-globin gene worldwide $[1,2]$. The ineffective red blood cell (RBC) synthesis in these patients due to unbalanced hemoglobin chains production cause increased RBCs turnover and anemia that can be ameliorated by blood transfusions [3]. Although recurrent blood transfusion could be an effective treatment and reduces disease-specific morbidity and mortality, it is a comprehensive source of iron overload that can have several side effects $[4,5]$. Despite iron chelation therapy, chronic transfusion therapy often leads to massive iron overload in liver, heart, brain, and endocrine organs and subsequent organ dysfunction that ultimately results in death $[3,6,7]$. Iron overload may also occur in patients who do not receive multiple blood transfusions due to the absorption from the gut [8]. Oxidative stress, inflammation, hepatic involvements, osteoporosis, and cardiac and renal insufficiency are major causes of iron overload related morbidity in patients with $\beta$-TM [9].

In the past decade, the protective activities of various herbal flavonoids have been investigated. Silybum marianum (St. Mary's thistle, milk thistle; Asteraceae/Flavonolignan) was widely used in traditional European medicine for 2000 years especially for the treatment of the liver, spleen, and gallbladder disorders [10]. The seeds are the active part of the plant and the main flavonoid of them is called silymarin which consists of a mixture of four flavonolignans (70$80 \%)$ : silibinin (silybin) (50\%), silychristin (20\%), silydianin $(10 \%)$, and isosilybin (5\%) [11]. Silybin is the most important biologically active component of silymarin complex [12].

In the present study, we investigated the protective properties of silymarin and its constituents in $\beta$-TM patients to 

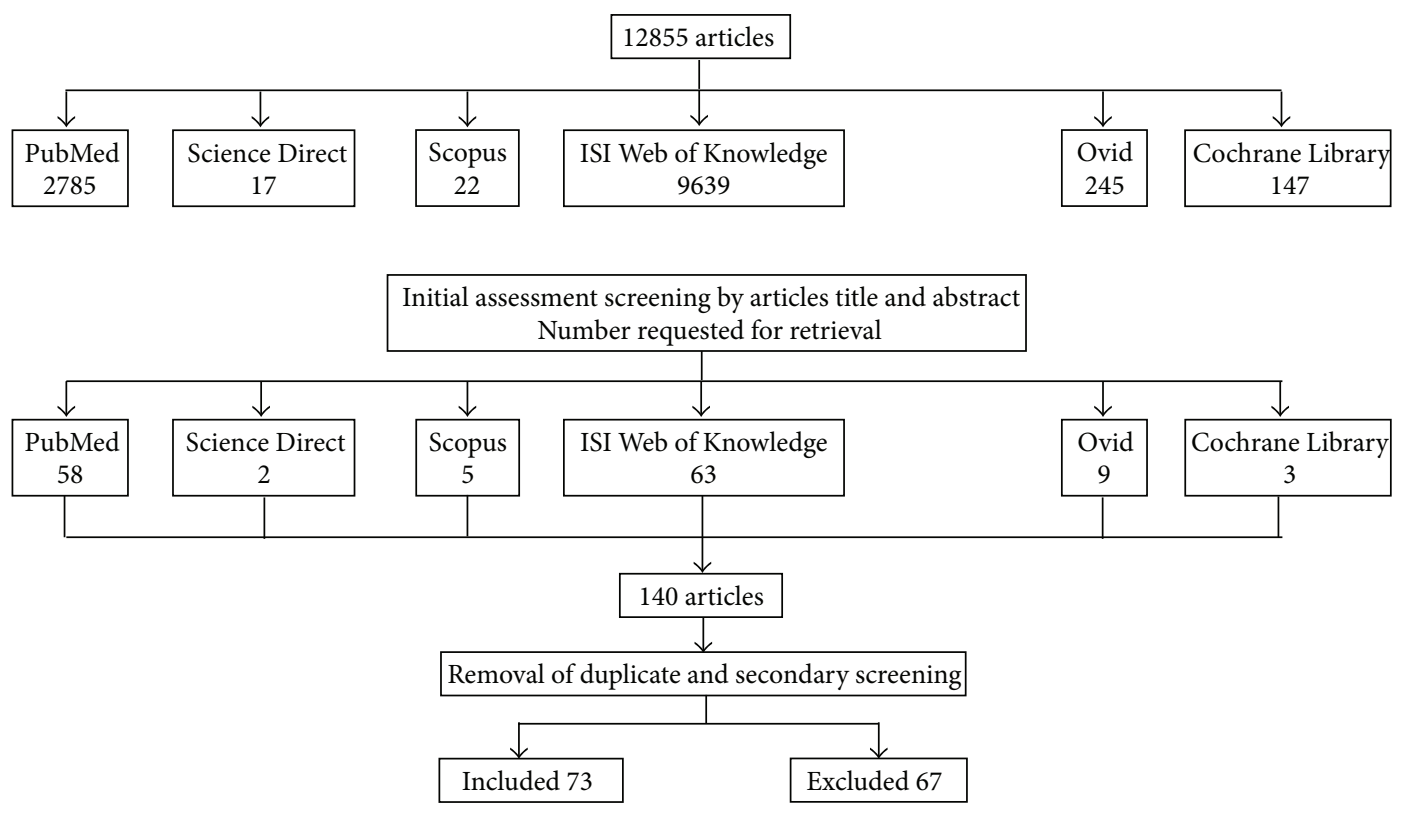

FIGURE 1: Literature search and retrieval flowchart.

consider the clinical applications of this herbal extract for protection against iron-induced organs damage.

\section{Methods}

We searched the English literature in PubMed, ISI Web of Knowledge, Science Direct, Scopus, Ovid, and Cochrane Library databases to find studies published from January 2000 to September 2015. The titles of the searches were appropriate MESH headings including "Milk thistle", "silymarin", "silybum", "silibinin", "silybin", "silydianin", "silychristin", "herbs", "medicinal plant", "natural product", "herbal medicine", "plant medicine", "phytomedicine", and "thalassemia". Moreover, in addition to the electronic searches, manual searches of reference lists used in all of the retrieved review articles and primary studies were carried out to identify other studies that were not found in the electronic searches. The literature was searched by two authors independently. The inclusion criteria of the papers were as follows: (1) the studies on antioxidant effects, iron chelating, liver protective, anti-inflammatory, immunomodulatory, and antiosteoporotic activities, and cardiac and renal protective effects that were conducted on animals and humans; (2) plant extracts or compounds isolated from plant. The exclusion criteria consisted of (1) the studies that were about an herbal formula and (2) the articles that were not written in English or translated to English. Two researchers independently read the full texts and extracted the following contents: publication data; study design; sample size; patient characteristics; treatment protocol; and outcome measures.

The search strategy generated 12855 titles and abstracts. After initial screening and evaluation, 12715 articles were rejected and 140 articles were founded to be potentially eligible for the review. These articles were retrieved for full text review. Removing duplicates and using secondary screening resulted in 73 articles to be included for the review (Figure 1).

\section{Results}

3.1. Antioxidant Effects. Iron toxicity in $\beta$-TM is the main cause of oxidative stress. Oxidative stress, associated with the formation of reactive oxygen species (ROS), plays an important role in the development of inflammation, decreased level of plasma antioxidants, depletion of erythrocyte glutathione (GSH), increased lipid peroxidation of RBC membranes, and immunosuppression in these patients $[13,14]$. Several studies have shown that silymarin modulates imbalance between cell survival and apoptosis through interference with the expressions of the cell cycle regulators and proteins involved in apoptosis [15]. Silymarin protects cells from ROS damages by increasing endogenous antioxidant enzymes such as glutathione peroxidase (GPx) and superoxide dismutase (SOD). Moreover, it also inhibits the activation of NF- $\kappa \mathrm{B}[16,17]$.

Alidoost et al. surveyed intracellular GSH and proliferative response of peripheral blood mononuclear cells (PBMC) before and after 72-hour incubation of PBMC with various concentrations of silymarin $(0,5,10$, or $20 \mu \mathrm{g} / \mathrm{mL})$ in 28 patients with $\beta$-TM and 28 healthy age-matched individuals [14]. Results of that study showed a significant restoration of GSH and its normalization in $\beta$-TM cells following treatment with silymarin. GSH is a primary intracellular antioxidant and plays an essential role in several functions in T cells [14]. Considerably, low levels of GSH and depressed proliferative response of PBMC in $\beta$-TM may be responsible for the cell mediated immune abnormalities in iron overload conditions [14]. These data indicate the benefit of using silymarin to normalize immune dysfunction via antioxidant and immunostimulatory activities in $\beta$-thalassemia major. 
Moreover, Jeong et al. found that silibinin can successfully prompt apoptosis and as a result it leads to human glioma tumor cells death through calpain-dependent mechanism involving protein kinase $\mathrm{C}$ (PKC), ROS, and apoptosisinducing factor (AIF) nuclear translocation [18].

3.2. Iron Chelation Effects. For the first time, Borsari et al. introduced silybin as a new iron-chelating agent [19] and since then the in vitro studies have showed that silybin has a high affinity for $\mathrm{Fe}$ (III) at acidic $\mathrm{pH}$ and makes an ironsilybin complex $[12,20]$. Consequently, some clinical trials have reported that silymarin and silybin may act as ironchelating agents in patients with $\beta$-TM $[11,21,22]$. These studies argued that treatment with silymarin and silybin leads to reduction in the body iron stores and decrease of serum ferritin level.

Navidi-Shishaone et al. investigated the effect of desferrioxamine (DFO) and silymarin combination therapy against kidney and heart iron deposition in an iron overload rat model. The iron overload condition was performed by iron dextran $(100 \mathrm{mg} / \mathrm{kg} /$ day $)$ every other day. Administration of iron dextran was stopped after 2 weeks and the animals were treated daily with combination of silymarin $(200 \mathrm{mg} /$ $\mathrm{kg} /$ day, intraperitoneally) and DFO (50 mg/kg/day, intraperitoneally). The results displayed that although coadministration of silymarin and DFO may be potentially considered as an iron chelator, combination of these two agents does not reduce the intensity of iron deposition in the kidney, liver, and heart [23]. In a clinical trial by Gharagozloo et al., 59 patients with $\beta$-TM were randomized into two groups. First group received silymarin plus DFO while DFO with placebo was administered for the second group for 3 months (Table 1 shown). Findings of the mentioned study indicated that the combination therapy was well tolerated and more effective than DFO alone in reducing serum ferritin level. However, no significant differences were detected between silymarin and placebo groups in serum ferritin level after 1.5 and 3 months of treatment. In that study, it was also argued that the observed slight changes in ferritin level between two groups probably may be because of small sample size. That was the first report showing the beneficial effects of silymarin in $\beta$ TM patients [11]. In another study, patients were treated with the combination of DFO and silymarin ( $420 \mathrm{mg} /$ day) or DFO plus placebo (49//versus 48//) for 9 months. Serum iron and total iron binding capacity (TIBC) levels were significantly reduced after silymarin therapy. Moreover, serum ferritin levels strongly decreased in silymarin group in comparison to placebo group (Table 1). That shows potential effectiveness of silymarin alone as an iron-chelating agent in reducing body iron load in $\beta$-TM [21]. Balouchi et al. stated that although $69.23 \%$ of patients have a little drop in the serum ferritin level in combination therapy group (DFO plus $420 \mathrm{mg} /$ day silymarin), reduction of serum ferritin level was not significant after 6 months (Table 1 shown). Besides, they mentioned that silymarin has iron chelator effects and the little sample size was the reason why the nonsignificant decrease in serum ferritin level was observed [24]. Recently, Hagag et al. investigated therapeutic effects of silymarin plus deferiprone (DFP) in $80 \beta$-TM patients with $>1000 \mathrm{ng} / \mathrm{mL}$ serum ferritin level
[22]. They indicated that, after treatment, the serum ferritin and iron levels were dramatically decreased. In addition, higher TIBC was also observed after combination therapy (Table 1). These findings are supported by results of their previous study with deferasirox (DFX) and silymarin combination therapy [25]. Moreover, after combination therapy, serum iron level was significantly decreased from $248.85 \pm$ 38.2 to $137.4 \pm 31.1 \mathrm{ng} / \mathrm{dL}(P=0.001)$. Based on the results of these two studies, it can be concluded that the iron chelator effects of silymarin are related to its ability of Fe (III) binding. Similarly, Bares et al. evaluated that administration of oral silybin for 12 weeks decreases body iron stores in patients with chronic hepatitis C [26]. It seems that silymarin could potentially have an iron-chelating effect via strong antioxidant activity and reducing nonhaem iron [20]. More studies are required to clarify the role of silymarin in the decrease of iron overload in clinical condition.

3.3. Hepatic Protection. Iron overload can affect various tissues including liver in patients with $\beta$-TM. Liver injury and chronic hepatitis (B and C) are serious medical problems in the transfusion dependent $\beta$-TM patients. The high incidence of hepatitis $C$ was observed in $\beta$-TM patients after a screening during a fourteen-year study (at two 7-year intervals; 19962002 and 2003-2009). Of the 395 patients, 109 (27.5\%) were anti-HCV positive, and 21 (19.2\%) out of these 109 cases were exposed after 1996. The incidence rate of HCV was 4.2/1000 person-years during that time. The incidence rates of $\mathrm{HCV}$ in the first and second seven-year periods were 6.2/1000 and 1.3/1000 person-years, respectively [27].

Silymarin has been extensively used as a hepatoprotective agent in Asia and Europe [18]. Although it has been widely used in the treatment of liver disease, few clinical trials have been conducted about its effects on patients. In animal models, silymarin was shown to protect the patients against liver injury induced by toxins [28]. Based on findings of cellular morphological changes in rat using light microscope, the protective roles of silymarin plus DFO on iron overloadinduced hepatotoxicity were introduced by Najafzadeh et al. [29]. The mentioned study showed antihepatotoxic effects of silymarin, improvement of liver function, and decrease of total protein and total albumin in animal models. Studies of silymarin at high concentrations in the HCV replicon system also show an effect on HCV core and NS5A gene expression [30, 31]. In these studies, an anticarcinogenic role of silymarin was argued to be the main mechanism of its actions [10]. The results of these studies demonstrate that silymarin has antiviral and hepatoprotective effects and it may be useful in the treatment of $\beta$-TM patients with hepatitis as a complementary approach.

3.4. Immunomodulatory and Anti-Inflammatory Effects. There are several immune abnormalities in transfusions dependent $\beta$-TM patients such as increased number and enhanced activities of suppressor T-cells (CD8), reduced proliferative capacity of helper T-cells (CD4), and decreased CD4/CD8 ratios [32-34]. Moreover, iron overload in $\beta$-TM patients reduces the proliferative activities of $\mathrm{T}$ cells $[35,36]$. Iron overload and continuous immune stimulation are the 


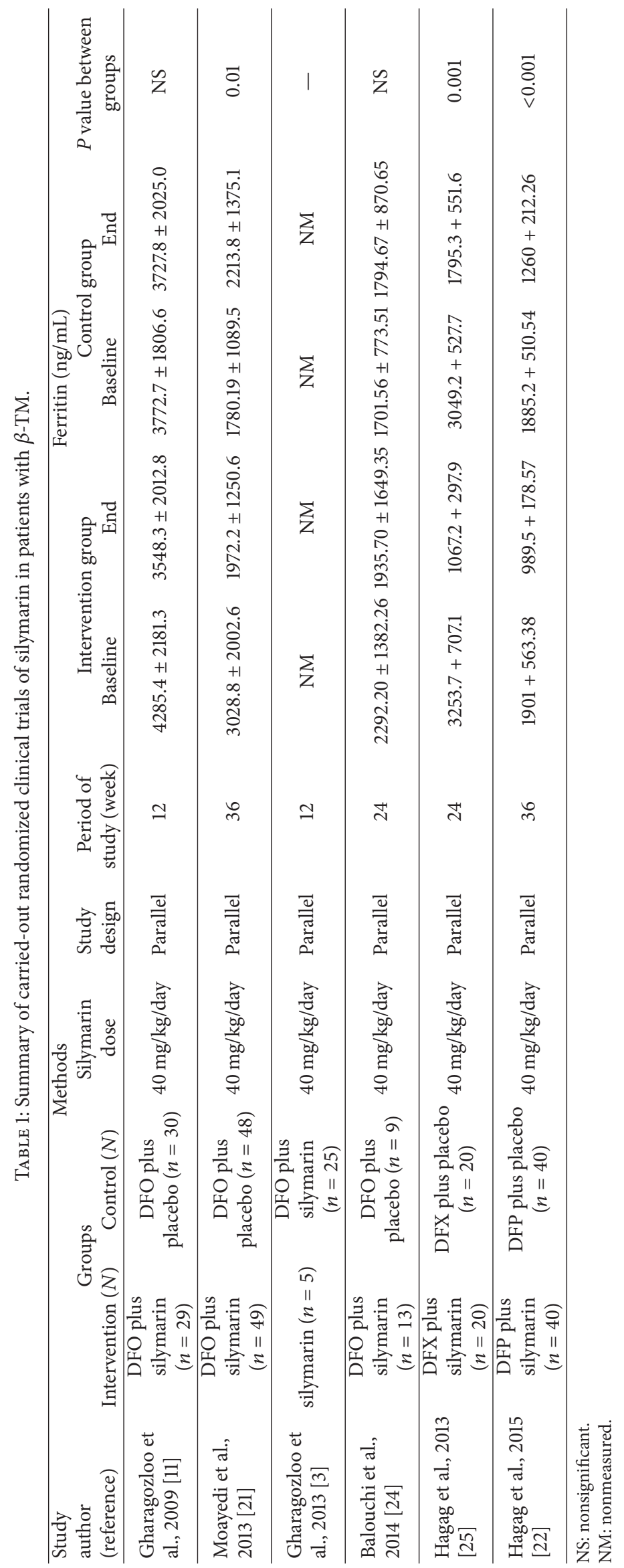


key causes of suppressed cell mediated immunity in these patients [36, 37].

Immunomodulatory and anti-inflammatory effects of silibinin have been shown in some studies. Silibinin inhibits tumor necrosis factor alpha (TNF- $\alpha$ ) production [38, 39]. Silibinin suppresses the growth of HMC-1 cells and it also decreases expression of proinflammatory cytokines through inhibition of NF- $\kappa$ B signaling pathway in HMC-1 human mast cells (such as TNF- $\alpha$, IL-6, and IL-8) [40]. An in vitro study showed that silymarin has anti-inflammatory and immunomodulatory effects through inhibition of NF- $\kappa$ B [41, 42]. Wilasrusmee et al. reported that in vitro treatment of PBMC with silymarin leads to restoration of the thiol status and increases $\mathrm{T}$ cell proliferation and activation, and it enhances interferon gamma (IFN $\gamma$ ), interleukin- (IL-) 4, and IL-10 secretions via stimulating of the lymphocytes in a dose dependent pattern [43]. So, they recommended the silymarin as a possible effective immunomodulatory herbal medication in the management of $\beta$-TM patients because of its antioxidant, cytoprotective, and iron-chelating activities [3].

Gharagozloo et al., in a 12-week randomized clinical trial, examined the immunomodulatory effects of silymarin. Twenty-five patients received DFO $(40 \mathrm{mg} / \mathrm{kg} /$ day $)$ and $420 \mathrm{mg}$ of silymarin daily as a combination therapy while five cases took only silymarin. The serum levels of neopterin and TNF- $\alpha$ were dramatically diminished in two groups. Neopterin is created by monocytes and macrophages upon stimulation with IFN- $\gamma$. Measurement of neopterin blood concentrations provides important information about the triggering of cellular immune activation in humans under the control of $\mathrm{T}$ helper cells type 1 . This analysis allows researchers to evaluate the extent of oxidative stress stimulated by the immune system [3]. Moreover, increased production of IFN $\gamma$ and IL- 4 was observed in activated T cells following silymarin therapy in both groups. Based on these results, Gharagozloo et al. concluded that silymarin may stimulate cell-mediated immune response via a direct effect on cytokine-producing mononuclear cells in $\beta$-TM. Besides, there were no evidences of lymphocyte subsets percentage, concentration of serum immunoglobulins, complement levels, and T cell proliferation between intervention groups [3].

Researchers proposed that probable iron-chelating and antioxidant activities of silymarin can be considered as an important mechanism of its immune-stimulatory effect. They also stated that silymarin has strong dose dependent immunomodulatory effects. Interestingly, it shows an immune-stimulatory activity at low doses $(40 / \mathrm{mg} / \mathrm{kg} / \mathrm{day})$ and immunosuppressive effects at high doses [3, 44]. Schümann et al. indicated that silymarin suppresses $\mathrm{T}$ celldependent liver injury and inhibits intrahepatic expression of TNF- $\alpha$, IFN- $\gamma$, IL- 4 , IL-2, and inducible nitric oxide synthase (iNOS) in in vitro condition [45]. It has been shown that silymarin strongly disturbs the activation of NF- $\kappa \mathrm{B}$ and mTOR in activated Tlymphocytes with inhibition of IL-2 and IFN- $\gamma$ production and cell proliferation $[46,47]$.

A clinical study investigated the immunomodulatory effect of silymarin $(420 \mathrm{mg} /$ day $)$ by measuring the serum levels of TGF- $\beta$, IL-10, IL-17, and IL-23 in patients with $\beta$ TM in comparison to healthy controls. The results showed a significant higher concentration of TGF- $\beta$ and IL-23 in the patient group than the controls. Among cytokines, only a significant reduction in serum IL-10 levels was found due to silymarin administration. In patients treated with silymarin, a fall in serum TGF- $\beta$ (38\%), IL-10 (84.6\%), IL-17 (61.5\%), and IL-23 (61.5\%) levels was noted. This data propose that the immune abnormality, inflammation, and immunosuppression caused by iron overload in $\beta$-TM patients could be modulated by silymarin [24]. These results suggest that silymarin and its compounds could ameliorate immune abnormalities and inflammation in $\beta$-TM patients.

3.5. Osteoprotective Effects. Osteoporosis is a common bonerelated metabolic disease characterized by low bone density and increased bone fragility and fractures [48]. Patients with $\beta$-TM are susceptible to osteopenia and osteoporosis. The mechanism of osteoporosis in these patients is multifactorial. Iron deposition in endocrine organs following multiple transfusion leads to impaired growth hormone secretion, hypothyroidism, hypoparathyroidism, lack of gonadal steroids, and vitamin $\mathrm{D}$ deficiency which contribute to the defect in achieving an acceptable bone density [49]. Recently, estrogenic and osteoprotective effects of silymarin were studied in animal models. Some studies found that silibinin has a potential to increase osteoblastogenesis and inhibit osteoclast formation by attenuating the downstream signaling cascades associated with receptor activator of NF- $\kappa$ B ligand or TNF- $\alpha$ in murine preosteoblastic cell. In addition, silibinin might act as bone morphogenetic protein (BMP) modulator, osteoprotective, and inhibitor of osteoclastic bone resorption. BMPs are a group of growth factors known as cytokines and metabologens that induce the development of bone and cartilage. BMPs are now considered to constitute a group of pivotal morphogenetic signals and orchestrating tissue architecture throughout the body [50,51]. Silymarin therapy may also heighten collagen secretion, osteocalcin transcription, and BMP expression [52]. Seidlová-Wuttke et al. demonstrated that silymarin is a selective estrogen receptor modulator (SERM) on the ER $\beta$-subtype of the estrogen receptor and it can be considered as pure ER $\beta$-specific ligands [53]. ER $\alpha$ and $\operatorname{ER} \beta$ are the classical estrogen receptors that engage in the regulation of many complex physiological processes in humans. Modulation of these receptors is now considered for the treatment and prevention of osteoporosis [54]. Although several studies have established the various roles of silymarin in both in vitro and in vivo models, the effect of silymarin and its flavonolignan components as an osteoprotective agent in clinical practice is required to be investigated.

3.6. Cardiac Protective Effects. Cardiac complications such as cardiomyopathy and heart failure secondary to iron overload are still the main cause of mortality in $\beta$-TM [55]. It has been shown that around $70 \%$ of deaths are related to this complication [56]. Recently, some randomized clinical trials were carried out on these patients regarding cardiac protective property of silymarin $[11,19,21]$. It seems that decrease of oxidative stress markers such as ROS inside the heart cells is caused by strong antioxidant properties of silymarin and their cytoprotective and anti-inflammatory effects could be 
responsible for cardioprotective effects [57, 58]. Moreover, silymarin protects cardiac myocytes via decrease of lactate dehydrogenase (LDH) and malondialdehyde (MDA) [59]. However, the cardiac protective effects of silymarin are not clear in clinical researches.

3.7. Renal Protective Effects. Renal dysfunction as result of tissue iron deposition is one of the main problems in patients with $\beta$-TM [60]. Currently, a few researches showed that silymarin can protect kidney against induced iron toxicity in $\beta$-TM and diabetics patients and also after chemotherapy in cancer patients [61-65]. Silymarin significantly can reduce kidney iron deposition in rat model and it has nephroprotective properties in acute iron overload animal models. Fallahzadeh et al. stated that silymarin can be considered as a new addition to the antidiabetic nephropathy armamentarium [66]. In this clinical trial, urinary albumin-creatinine ratio (UACR), urinary levels of $\mathrm{TNF}-\alpha$, and urinary and serum levels of MDA were significantly reduced in the intervention group. Silymarin could improve diabetic nephropathy at $140 \mathrm{mg}$ doses 3 times a day for 3 months in type 2 diabetes patients with macroalbuminuria. For better understanding of the renal protective effects of silymarin, more studies are recommended to carry out, especially, evaluation of administration of silymarin in combination with standard iron chelation.

\section{Conclusion}

According to the current review, it seems that silymarin plus standard iron chelation may have a better result to protect organ induced iron overload. Silymarin which is a safe and well-tolerated adjuvant is introduced as a drug without adverse effects in many clinical studies. We recommend that more well-designed randomized clinical trials are required considering silymarin pharmacokinetic behavior in order to generate strong evidence about improvement of iron overload complications among patients with $\beta$-TM.

\section{Conflict of Interests}

None of the authors have any conflict of interests to disclose.

\section{References}

[1] N. Achoubi, M. Asghar, K. N. Saraswathy, and B. Murry, "Prevalence of $\beta$-thalassemia and hemoglobin e in two migrant populations of Manipur, North East India," Genetic Testing and Molecular Biomarkers, vol. 16, no. 10, pp. 1195-1200, 2012.

[2] M. Kosaryan, K. Vahidshahi, H. Karami, M. A. Forootan, and M. Ahangari, "Survival of thalassemic patients referred to the Boo Ali Sina teaching hospital, Sari, Iran," Hemoglobin, vol. 31, no. 4, pp. 453-462, 2007.

[3] M. Gharagozloo, M. Karimi, and Z. Amirghofran, "Immunomodulatory effects of silymarin in patients with $\beta$-thalassemia major," International Immunopharmacology, vol. 16, no. 2, pp. 243-247, 2013.

[4] J.-A. Ribeil, J.-B. Arlet, M. Dussiot, I. Cruz Moura, G. Courtois, and O. Hermine, "Ineffective erythropoiesis in $\beta$-thalassemia,"
The Scientific World Journal, vol. 2013, Article ID 394295, 11 pages, 2013.

[5] C. Sengsuk, O. Tangvarasittichai, P. Chantanaskulwong et al., "Association of iron overload with oxidative stress, hepatic damage and dyslipidemia in transfusion-dependent $\beta$-thalassemia/HbE patients," Indian Journal of Clinical Biochemistry, vol. 29, no. 3, pp. 298-305, 2014.

[6] N. E. Piloni, V. Fermandez, L. A. Videla, and S. Puntarulo, "Acute iron overload and oxidative stress in brain," Toxicology, vol. 314, no. 1, pp. 174-182, 2013.

[7] E. Vichinsky, E. Butensky, E. Fung et al., "Comparison of organ dysfunction in transfused patients with SCD or $\beta$ thalassemia," American Journal of Hematology, vol. 80, no. 1, pp. 70-74, 2005.

[8] T. E. D. J. dos Santos, G. F. de Sousa, M. C. Barbosa, and R. P. Gonçalves, "The role of iron overload on oxidative stress in sickle cell anemia," Biomarkers in Medicine, vol. 6, no. 6, pp. 813819, 2012.

[9] M. Y. Abdalla, M. Fawzi, S. R. Al-Maloul, N. El-Banna, R. F. Tayyem, and I. M. Ahmad, "Increased oxidative stress and iron overload in Jordanian $\beta$-thalassemic children," Hemoglobin, vol. 35, no. 1, pp. 67-79, 2011.

[10] E. Shaker, H. Mahmoud, and S. Mnaa, "Silymarin, the antioxidant component and Silybum marianum extracts prevent liver damage," Food and Chemical Toxicology, vol. 48, no. 3, pp. 803806, 2010.

[11] M. Gharagozloo, B. Moayedi, M. Zakerinia et al., "Combined therapy of silymarin and desferrioxamine in patients with $\beta$ thalassemia major: a randomized double-blind clinical trial," Fundamental \& Clinical Pharmacology, vol. 23, no. 3, pp. 359365, 2009.

[12] M. Gharagozloo, Z. Khoshdel, and Z. Amirghofran, “The effect of an iron (III) chelator, silybin, on the proliferation and cell cycle of Jurkat cells: a comparison with desferrioxamine," European Journal of Pharmacology, vol. 589, no. 1-3, pp. 1-7, 2008.

[13] A. Svobodová, D. Walterová, and J. Psotová, "Influence of silymarin and its flavonolignans on $\mathrm{H}_{2} \mathrm{O}_{2}$-induced oxidative stress in human keratinocytes and mouse fibroblasts," Burns, vol. 32, no. 8, pp. 973-979, 2006.

[14] F. Alidoost, M. Gharagozloo, B. Bagherpour et al., "Effects of silymarin on the proliferation and glutathione levels of peripheral blood mononuclear cells from $\beta$-thalassemia major patients," International Immunopharmacology, vol. 6, no. 8, pp. 1305-1310, 2006

[15] K. Ramasamy and R. Agarwal, "Multitargeted therapy of cancer by silymarin," Cancer Letters, vol. 269, no. 2, pp. 352-362, 2008.

[16] M. C. Comelli, U. Mengs, C. Schneider, and M. Prosdocimi, "Toward the definition of the mechanism of action of silymarin: activities related to cellular protection from toxic damage induced by chemotherapy," Integrative Cancer Therapies, vol. 6, no. 2, pp. 120-129, 2007.

[17] A. J. Hanje, B. Fortune, M. Song, D. Hill, and C. McClain, "The use of selected nutrition supplements and complementary and alternative medicine in liver disease," Nutrition in Clinical Practice, vol. 21, no. 3, pp. 255-272, 2006.

[18] J. C. Jeong, W. Y. Shin, T. H. Kim et al., "Silibinin induces apoptosis via calpain-dependent AIF nuclear translocation in U87MG human glioma cell death," Journal of Experimental and Clinical Cancer Research, vol. 30, article 44, 2011.

[19] M. Borsari, C. Gabbi, F. Ghelfi et al., "Silybin, a new iron-chelating agent," Journal of Inorganic Biochemistry, vol. 85, no. 2-3, pp. 123-129, 2001. 
[20] C. Hutchinson, A. Bomford, and C. A. Geissler, "The ironchelating potential of silybin in patients with hereditary haemochromatosis," European Journal of Clinical Nutrition, vol. 64, no. 10, pp. 1239-1241, 2010.

[21] B. Moayedi, M. Gharagozloo, N. Esmaeil, M. R. Maracy, H. Hoorfar, and M. Jalaeikar, "A randomized double-blind, placebo-controlled study of therapeutic effects of silymarin in $\beta$-thalassemia major patients receiving desferrioxamine," European Journal of Haematology, vol. 90, no. 3, pp. 202-209, 2013.

[22] A. Hagag, M. Elfaragy, S. Elrifaey, and A. Abd El-Lateef, "Therapeutic value of combined therapy with Deferiprone and Silymarin as iron chelators in Egyptian Children with Beta Thalassemia major," Infectious Disorders-Drug Targets, vol. 15, no. 3, pp. 189-195, 2015.

[23] M. Navidi-Shishaone, S. Mohhebi, M. Nematbakhsh et al., "Coadministration of silymarin and deferoxamine against kidney, liver and heart iron deposition in male iron overload rat model," International Journal of Preventive Medicine, vol. 5, no. 1, pp. 110-116, 2014.

[24] S. Balouchi, M. Gharagozloo, N. Esmaeil, M. Mirmoghtadaei, and B. Moayedi, "Serum levels of TGF $\beta$, IL-10, IL-17, and IL-23 cytokines in $\beta$-thalassemia major patients: the impact of silymarin therapy," Immunopharmacology and Immunotoxicology, vol. 36, no. 4, pp. 271-274, 2014.

[25] A. A. Hagag, M. S. Elfrargy, R. A. Gazar, and A. E. A. El-Lateef, "Therapeutic value of combined therapy with deferasirox and silymarin on iron overload in children with beta thalassemia," Mediterranean Journal of Hematology and Infectious Diseases, vol. 5, no. 1, pp. 1-7, 2013.

[26] J. M. Bares, J. Berger, J. E. Nelson et al., "Silybin treatment is associated with reduction in serum ferritin in patients with chronic hepatitis C," Journal of Clinical Gastroenterology, vol. 42, no. 8, pp. 937-944, 2008.

[27] A. Azarkeivan, M. N. Toosi, M. Maghsudlu, S. A. Kafiabad, B. Hajibeigi, and M. Hadizadeh, "The incidence of hepatitis $C$ in patients with thalassemia after screening in blood transfusion centers: a fourteen-year study," Transfusion, vol. 52, no. 8, pp. 1814-1818, 2012.

[28] R. P. Singh and R. Agarwal, "Flavonoid antioxidant silymarin and skin cancer," Antioxidants and Redox Signaling, vol. 4, no. 4, pp. 655-663, 2002.

[29] H. Najafzadeh, M. R. Jalali, H. Morovvati, and F. Taravati, "Comparison of the prophylactic effect of silymarin and deferoxamine on iron overload-induced hepatotoxicity in rat," Journal of Medical Toxicology, vol. 6, no. 1, pp. 22-26, 2010.

[30] M. W. Fried, V. J. Navarro, N. Afdhal et al., "Effect of silymarin (milk thistle) on liver disease in patients with chronic hepatitis $\mathrm{C}$ unsuccessfully treated with interferon therapy: a randomized controlled trial," The Journal of the American Medical Association, vol. 308, no. 3, pp. 274-282, 2012.

[31] V. Bonifaz, Y. Shan, R. W. Lambrecht, S. E. Donohue, D. Moschenross, and H. L. Bonkovsky, "Effects of silymarin on hepatitis $\mathrm{C}$ virus and haem oxygenase-1 gene expression in human hepatoma cells," Liver International, vol. 29, no. 3, pp. 366-373, 2009.

[32] E. M. Walker Jr. and S. M. Walker, "Effects of iron overload on the immune system," Annals of Clinical \& Laboratory Science, vol. 30, no. 4, pp. 354-365, 2000.

[33] G. Weiss, "Iron and immunity: a double-edged sword," European Journal of Clinical Investigation, vol. 32, supplement 1, pp. 70-78, 2002.
[34] D. Farmakis, A. Giakoumis, A. Aessopos, and E. Polymeropoulos, "Pathogenetic aspects of immune deficiency associated with B thalassemia," Medical Science Review, vol. 9, no. 1, pp. RA19RA22, 2003.

[35] S. Cunningham-Rundles, P. J. Giardina, R. W. Grady, C. Califano, P. McKenzie, and M. De Sousa, "Effect of transfusional iron overload on immune response," Journal of Infectious Diseases, vol. 182, supplement 1, pp. S115-S121, 2000.

[36] Ü. Ezer, F. Gülderen, V. K. Çulha, N. Akgül, and Ö. Gürbüz, "Immunological status of Thalassemia syndrome," Pediatric Hematology and Oncology, vol. 19, no. 1, pp. 51-58, 2002.

[37] M. Gharagozloo, M. Karimi, and Z. Amirghofran, "Doublefaced cell-mediated immunity in $\beta$-thalassemia major: stimulated phenotype versus suppressed activity," Annals of Hematology, vol. 88, no. 1, pp. 21-27, 2009.

[38] L. Al-Anati, E. Essid, R. Reinehr, and E. Petzinger, "Silibinin protects OTA-mediated TNF- $\alpha$ release from perfused rat livers and isolated rat Kupffer cells," Molecular Nutrition \& Food Research, vol. 53, no. 4, pp. 460-466, 2009.

[39] J. C. Peraçoli, M. V. C. Rudge, and M. T. S. Peraçoli, “Tumor necrosis factor-alpha in gestation and puerperium of women with gestational hypertension and pre-eclampsia," American Journal of Reproductive Immunology, vol. 57, no. 3, pp. 177-185, 2007.

[40] B.-R. Kim, H.-S. Seo, J.-M. Ku et al., "Silibinin inhibits the production of pro-inflammatory cytokines through inhibition of NF- $\kappa$ B signaling pathway in HMC-1 human mast cells," Inflammation Research, vol. 62, no. 11, pp. 941-950, 2013.

[41] C. Morishima, M. C. Shuhart, C. C. Wang et al., "Silymarin inhibits in vitro $\mathrm{T}$-cell proliferation and cytokine production in hepatitis C virus infection," Gastroenterology, vol. 138, no. 2, pp. 671.e2-681.e2, 2010.

[42] S. J. Polyak, C. Morishima, V. Lohmann et al., "Identification of hepatoprotective flavonolignans from silymarin," Proceedings of the National Academy of Sciences of the United States of America, vol. 107, no. 13, pp. 5995-5999, 2010.

[43] C. Wilasrusmee, S. Kittur, G. Shah et al., "Immunostimulatory effect of Silybum Marianum (milk thistle) extract," Medical Science Monitor, vol. 8, no. 11, pp. BR439-BR443, 2002.

[44] M. Gharagozloo and Z. Amirghofran, "Effects of silymarin on the spontaneous proliferation and cell cycle of human peripheral blood leukemia T cells," Journal of Cancer Research and Clinical Oncology, vol. 133, no. 8, pp. 525-532, 2007.

[45] J. Schümann, J. Prockl, A. K. Kiemer, A. M. Vollmar, R. Bang, and G. Tiegs, "Silibinin protects mice from T cell-dependent liver injury," Journal of Hepatology, vol. 39, no. 3, pp. 333-340, 2003.

[46] M. Gharagozloo, E. Velardi, S. Bruscoli et al., "Silymarin suppress $\mathrm{CD} 4^{+} \mathrm{T}$ cell activation and proliferation: effects on NF- $\kappa \mathrm{B}$ activity and IL-2 production," Pharmacological Research, vol. 61, no. 5, pp. 405-409, 2010.

[47] M. Gharagozloo, E. N. Javid, A. Rezaei, and K. Mousavizadeh, "Silymarin inhibits cell cycle progression and mTOR activity in activated human T cells: therapeutic implications for autoimmune diseases," Basic \& Clinical Pharmacology \& Toxicology, vol. 112, no. 4, pp. 251-256, 2013.

[48] J.-L. Kim, Y.-H. Kim, M.-K. Kang, J.-H. Gong, S.-J. Han, and Y.H. Kang, "Antiosteoclastic activity of milk thistle extract after ovariectomy to suppress estrogen deficiency-induced osteoporosis," BioMed Research International, vol. 2013, Article ID 919374, 11 pages, 2013. 
[49] N. Valizadeh, F. Farrokhi, V. Alinejad, S. S. Mardani, S. Hejazi, and M. Noroozi, "Bone density in transfusion dependent thalassemia patients in Urmia, Iran," Iranian Journal of Pediatric Hematology and Oncology, vol. 4, no. 2, pp. 68-71, 2014.

[50] C. V. Kavitha, G. Deep, S. C. Gangar, A. K. Jain, C. Agarwal, and R. Agarwal, "Silibinin inhibits prostate cancer cells-and RANKL-induced osteoclastogenesis by targeting NFATc1, NF$\kappa \mathrm{B}$, and AP-1 activation in RAW264.7 cells," Molecular Carcinogenesis, vol. 53, no. 3, pp. 169-180, 2014.

[51] X. Ying, L. Sun, X. Chen et al., "Silibinin promotes osteoblast differentiation of human bone marrow stromal cells via bone morphogenetic protein signaling," European Journal of Pharmacology, vol. 721, no. 1-3, pp. 225-230, 2013.

[52] J.-L. Kim, S.-H. Park, D. Jeong, J.-S. Nam, and Y.-H. Kang, "Osteogenic activity of silymarin through enhancement of alkaline phosphatase and osteocalcin in osteoblasts and tibiafractured mice," Experimental Biology and Medicine, vol. 237, no. 4, pp. 417-428, 2012.

[53] D. Seidlová-Wuttke, T. Becker, V. Christoffel, H. Jarry, and W. Wuttke, "Silymarin is a selective estrogen receptor $\beta(\mathrm{ER} \beta)$ agonist and has estrogenic effects in the metaphysis of the femur but no or antiestrogenic effects in the uterus of ovariectomized (ovx) rats," The Journal of Steroid Biochemistry and Molecular Biology, vol. 86, no. 2, pp. 179-188, 2003.

[54] I. Paterni, C. Granchi, J. A. Katzenellenbogen, and F. Minutolo, "Estrogen receptors alpha $(\mathrm{ER} \alpha)$ and beta $(\mathrm{ER} \beta)$ : subtypeselective ligands and clinical potential," Steroids, vol. 90, pp. 1329, 2014.

[55] M. A. Tanner, R. Galanello, C. Dessi et al., "A randomized, placebo-controlled, double-blind trial of the effect of combined therapy with deferoxamine and deferiprone on myocardial iron in thalassemia major using cardiovascular magnetic resonance," Circulation, vol. 115, no. 14, pp. 1876-1884, 2007.

[56] C. Borgna-Pignatti, M. D. Cappellini, P. De Stefano et al., "Cardiac morbidity and mortality in deferoxamine- or deferipronetreated patients with thalassemia major," Blood, vol. 107, no. 9, pp. 3733-3737, 2006.

[57] A. Zholobenko and M. Modriansky, "Silymarin and its constituents in cardiac preconditioning," Fitoterapia, vol. 97, pp. 122-132, 2014.

[58] B. A.-S. Moayedi Esfahani, N. Reisi, and M. Mirmoghtadaei, "Evaluating the safety and efficacy of silymarin in $\beta$-thalassemia patients: a review," Hemoglobin, vol. 39, no. 2, pp. 75-80, 2015.

[59] B. Zhou, L.-J. Wu, N.-H. Li et al., "Silibinin protects against isoproterenol-induced rat cardiac myocyte injury through mitochondrial pathway after up-regulation of SIRT1," Journal of Pharmacological Sciences, vol. 102, no. 4, pp. 387-395, 2006.

[60] M. Economou, N. Printza, A. Teli et al., "Renal dysfunction in patients with beta-thalassemia major receiving iron chelation therapy either with deferoxamine and deferiprone or with deferasirox," Acta Haematologica, vol. 123, no. 3, pp. 148-152, 2010.

[61] A. Baradaran, "Comment on: the protective role of silymarin and deferoxamine against iron dextran-induced renal iron deposition in male rats," International Journal of Preventive Medicine, vol. 4, no. 6, pp. 734-735, 2013.

[62] M. Nematbakhsh, Z. Pezeshki, B.-A. Moaeidi et al., "Protective role of silymarin and deferoxamine against iron dextraninduced renal iron deposition in male rats," International Journal of Preventive Medicine, vol. 4, no. 3, pp. 286-292, 2013.
[63] C. Ninsontia, K. Pongjit, C. Chaotham, and P. Chanvorachote, "Silymarin selectively protects human renal cells from cisplatininduced cell death," Pharmaceutical Biology, vol. 49, no. 10, pp. 1082-1090, 2011.

[64] G. Kaur, M. Athar, and M. S. Alam, "Dietary supplementation of silymarin protects against chemically induced nephrotoxicity, inflammation and renal tumor promotion response," Investigational New Drugs, vol. 28, no. 5, pp. 703-713, 2010.

[65] N. Sheela, M. A. Jose, D. Sathyamurthy, and B. N. Kumar, "Effect of silymarin on streptozotocin-nicotinamide-induced type 2 diabetic nephropathy in rats," Iranian Journal of Kidney Diseases, vol. 7, no. 2, pp. 117-123, 2013.

[66] M. K. Fallahzadeh, B. Dormanesh, M. M. Sagheb et al., "Effect of addition of silymarin to renin-angiotensin system inhibitors on proteinuria in type 2 diabetic patients with overt nephropathy: a randomized, double-blind, placebo-controlled trial," American Journal of Kidney Diseases, vol. 60, no. 6, pp. 896-903, 2012. 

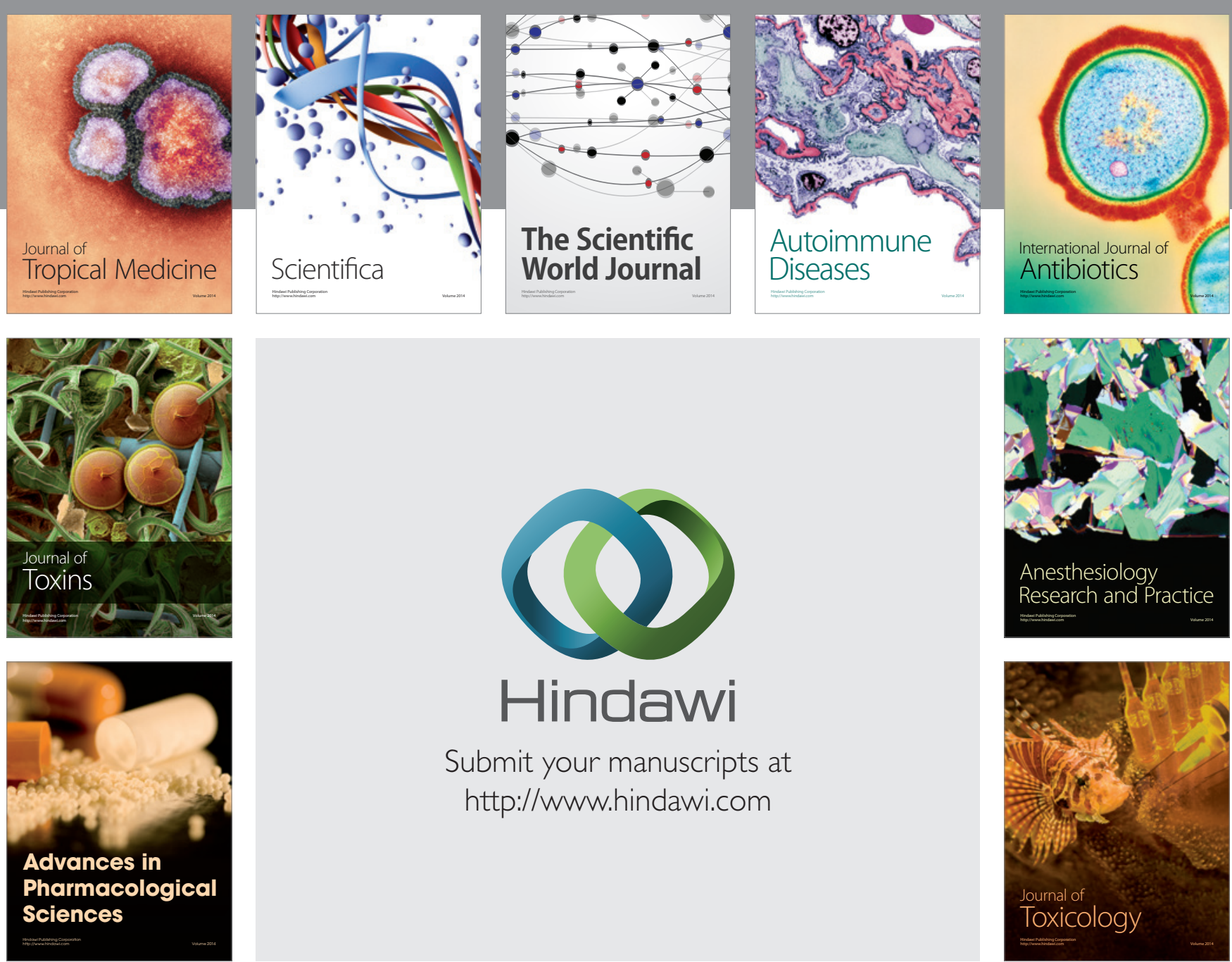

\section{Hindawi}

Submit your manuscripts at

http://www.hindawi.com
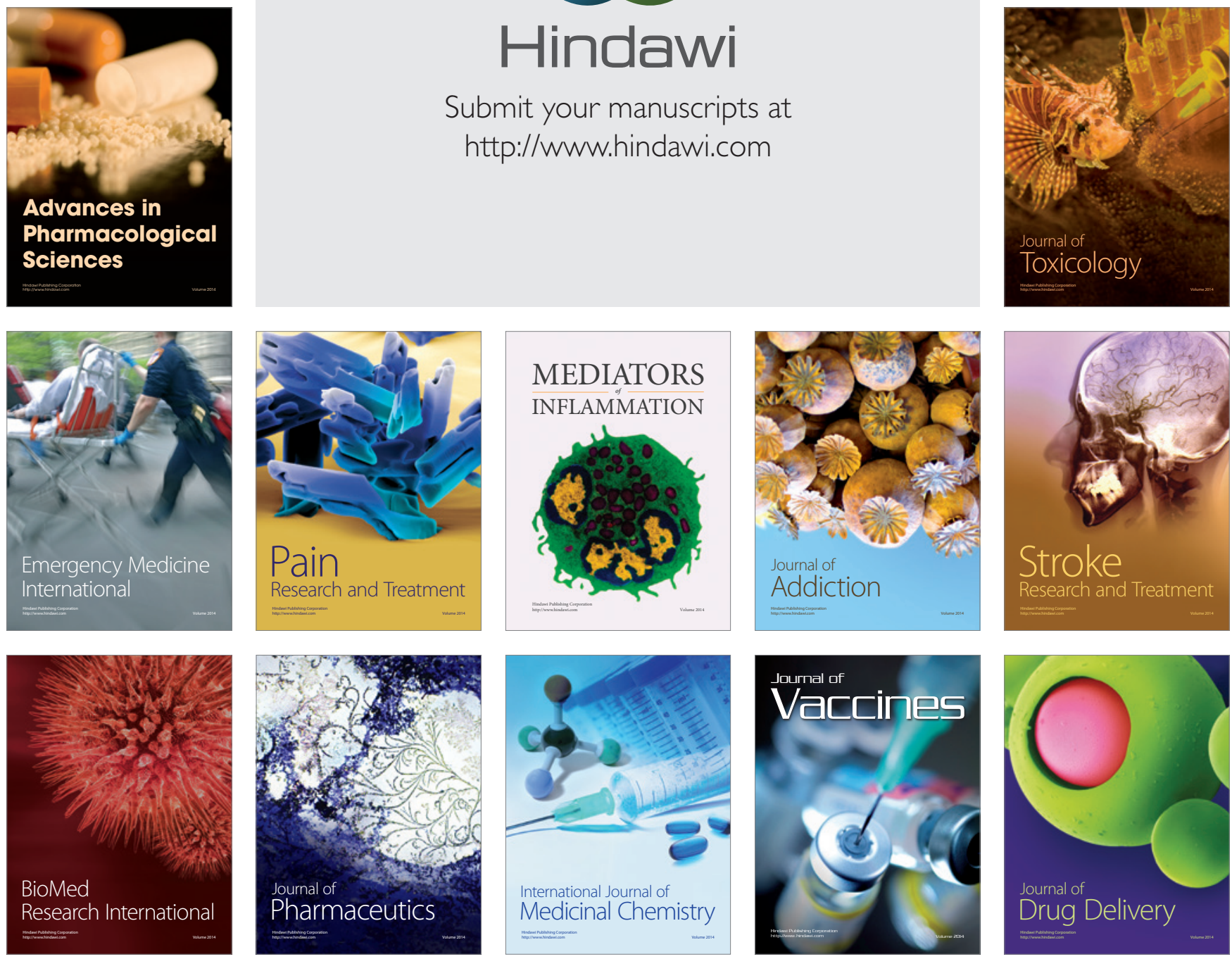